\title{
Two measurement methods of motor ulnar nerve conduction velocity at the elbow: A comparative study
}

\author{
K. Azma, K. Bahmanteimoury, B. Tavana, F. R. Moghaddam, N. M. Moghaddam, H. Mahmoudi* \\ Department of Physical Medicine and Rehabilitation, Army University of Medical Sciences, Tehran and *Rafsanjan University of \\ Medical Sciences, Rafsanjan, Iran
}

\begin{abstract}
Background: Electrodiagnostically, localization of ulnar nerve lesions, which commonly occurs at the elbow, is sometimes problematic. Measurement of motor ulnar nerve conduction velocity (NCV) at the elbow is amongst the most popular techniques to diagnose ulnar neuropathy. In this method, recording from the first dorsal interosseous muscle (FDI) is suggested to be more sensitive than the abductor digiti minimi (ADM). However, the criterion for abnormality is based on the normal values recorded from ADM. Aims: To determine the normal values of Ulnar motor NCV using FDI and ADM and the difference between the values obtained from FDI and ADM. Additionally, to measure the amount of reduction of NCV across the elbow for each recording site. Materials and Methods: This was a crosssectional study performed on 50 healthy volunteers (100 nerves). All subjects were in the same condition regarding joint position and surface hand temperature. We recorded ulnar NCV at forearm and across the elbow with recording electrode on both FDI and ADM, simultaneously. Results and Conclusions: The mean NCV at the elbow recorded from $A D M$ and FDI were $62.65 \pm 7.62 \mathrm{~m} / \mathrm{s}$ and $60.49 \pm 7.42 \mathrm{~m} / \mathrm{s}$ respectively, showing significant difference. The ulnar minimum normal NCVs recorded from ADM and FDI were $47.4 \mathrm{~m} / \mathrm{s}$ and $45.6 \mathrm{~m} / \mathrm{s}$, respectively. If the normal values of ADM are used as the basis for recording from FDI, it could lead to false-positive diagnosis of cases suspicious of ulnar neuropathy. Therefore it is preferred to use the normal values of FDI itself while recording.
\end{abstract}

Key words: Abductor digiti minimi muscle, conduction velocity, first dorsal interosseous muscle, ulnar nerve damage

\section{Introduction}

After median nerve, lesions of the ulnar nerve are amongst the most common injuries of the peripheral nerves of the upper extremity. ${ }^{[1,2]}$ Meanwhile, elbow is the most common region for its lesions; ${ }^{[3]}$ however, they may occur in other regions such as shoulder, elbow, forearm, wrist and palm. Although this type of neuropathy is commonly observed in general population, ${ }^{[4]}$ localization of its lesions in the elbow is problematic. Therefore, among suggested techniques, measurement of motor ulnar nerve conduction velocity (NCV) at the elbow is more remarkable. ${ }^{[1,5,6]}$ There are, of course, some studies indicating that the measurement of the sensory NCV is more sensitive ${ }^{[1,7,8]}$ In the method of motor NCV, which is performed more commonly, some investigators believe that it would be more sensitive to record NCV from first dorsal interosseous (FDI) muscle instead of abductor digiti minimi (ADM). Nonetheless, the criterion for being abnormal in both methods is based on the normal range obtained from ADM muscle. However, one study used special NCS FDI reference values. ${ }^{[9]}$

The objective of this study is to determine the normal values of the mean ulnar motor NCV using FDI as well as ADM instead of determining the difference between the values obtained from the FDI and ADM. Additionally, to measure the amount of reduction of NCV across the elbow from recording of each muscle.

\section{Materials and Methods}

A cross-sectional study was performed on 50 healthy volunteers without any signs and symptoms of ulnar neuropathy. All the volunteers came to the clinic of Physical Medicine and Rehabilitation at '501 Military' Hospital from December 2005 to April 2006.

All the volunteers underwent comprehensive systemic examination and were reassured of being healthy. The study was explained and a consent form was obtained from all of them. The thermometer measured the temperature of their hands. The temperature was increased to reach $32^{\circ} \mathrm{C}$ using an infrared device whenever 
it was less than $32^{\circ} \mathrm{C}$. Then we examined the subject in supine position with his shoulder externally rotated and $90^{\circ}$ abducted, his elbow flexed $135^{\circ}$ and his wrist in the neutral position.

The compound muscle action potentials (CMAPs) were recorded by a 2-channel EMG machine (Medtronic, Model SW7, Version 5) simultaneously using the same disc electrode type. To record from the ADM muscle, the $\mathrm{E}_{1}$ electrode was placed on the muscle's bulk between the pisiform osseous prominence and the $5^{\text {th }}$ metacarpophalangeal joint (MCPJ). The $\mathrm{E}_{2}$ electrode was placed on the distal portion of $2^{\text {nd }}$ MCPJ. To record from FDI, the $\mathrm{E}_{1}$ electrode was positioned on the muscle's bulk between the first and second metacarpal bones, while the $\mathrm{E}_{2}$ electrode was placed distal to $2^{\text {nd }} \mathrm{MCPJ}$.

The ground electrode was located between the sites of stimulation and recording. The stimulatory electrode was bipolar, superficial. Additionally, the distance between the anode and cathode was $3 \mathrm{~cm}$.

The sites of stimulation included:

1. Wrist (WR): $8 \mathrm{~cm}$ proximal to $\mathrm{E}_{1}$ disc's center in ADM's region

2. Below the elbow (BE): $4 \mathrm{~cm}$ below the medial epicondyle

3. Above the elbow (AE): $6 \mathrm{~cm}$ above the medial epicondyle.

Each stimulation was supramaximal, which means it was 25\% more than the intensity creating maximal CMAP amplitude. In each case a pulse duration of $100 \mathrm{~ms}$ was used, increasing the intensity from zero to the maximal level. After recording of CAMP, the position of latency marker was set in initial reflection from baseline. The parameters of the electromyography apparatus were adjusted as follows: Sensitivity $=5 \mathrm{mV} /$ div, sweep speed $=2 \mathrm{~ms} /$ div, low filter was $10 \mathrm{~Hz}$ and high filter was $10000 \mathrm{~Hz}$.

The collected data were evaluated by the SPSS (Version 10) program. We used Smirnov test for determining the normal distribution of the data and paired $t$-test for evaluating the significance of the difference between the means were done. A $P<0.05$ was considered statistically significant.

\section{Results}

50 healthy volunteers entered the study. About thirtysix $(72 \%)$ of them were male and $14(28 \%)$ were female. The mean age was $36.8 \pm 6.6$ (range: $16-50$ ) years old. The measurements were all done in both hands for all the volunteers.

The distribution of ulnar NCV at the elbow and the forearm, also the distribution of the difference between its NCV in these two regions recorded from ADM and FDI were all normal according to the Smirnov, skewness, and kurtosis tests.

The mean NCV of motor ulnar at the elbow recorded from $\mathrm{ADM}$ was $62.65 \pm 7.62 \mathrm{~m} / \mathrm{s}$, whereas in the case of FDI the mean would be $60.49 \pm 7.42 \mathrm{~m} / \mathrm{s}$. Confidence interval was 95\% according to the paired $t$-test $(P<0.0001$, $P$ - value $=7.66$ ), they show a significant difference.

The minimum normal value of the ulnar NCV across the elbow was $47.39 \mathrm{~m} / \mathrm{s}$ when recorded from ADM and $45.65 \mathrm{~m} / \mathrm{s}$ in case of FDI.

The mean difference between the ulnar NCV across the elbow and across the forearm was $-1.19 \pm 7.62 \mathrm{~m} / \mathrm{s}$ when recorded from ADM. However the mean difference was $2.39 \pm 7.85 \mathrm{~m} / \mathrm{s}$ when recorded from FDI. Considering the paired $t$-test, they have also a significant difference $(P<0.0001, t$ - value $=3.97)$.

The minimal normal range difference between ulnar NCV at the elbow and the forearm from ADM and FDI were 16.4 and $18.11 \mathrm{~m} / \mathrm{s}$ recorded, respectively. The data are summarized in the Tables 1 and 2.

\section{Discussion}

In a series of studies performed first by Dejerine et al. and afterwards by other investigators, it has been shown that the fascicles of the hand muscles especially FDI and the distal sensory fibers of digits are separated in the

Table 1: Comparison of nerve conduction velocity values between abductor digiti minimi and first dorsal interosseous recording
Nerve conduction

velocity

Abductor digiti minimi

Elbow

First dorsal interosseous

Abductor digiti minimi

Forearm

First dorsal interosseous

Abductor digiti minimi

Differences between

elbow and forearm values

First dorsal interosseous

${ }^{*} P$-value $<0.05$ was considered significant

Table 2: Comparison of nerve conduction velocity values between left and right elbow, forearm, abductor digiti minimi, and first dorsal interosseous recording

\section{Nerve conduction}

velocity

Right abductor digiti minimi

Elbow

No. recordings Mean SD

100

62.6 to 0.76

60.5 to 0.74

100

63.8 to 0.366

2.9 to 0.38

100

100

-1.19 to 0.76

-2.39 to 0.78

$<0.001$
Left abductor digiti minimi

Right first dorsal interosseous

Elbow

Left first dorsal interosseous

Right first dorsal interosseous

Forearm

Left first dorsal interosseous

Right abductor digiti minimi

Forearm

Left abductor digiti minimi
No. subjects Mean SD ${ }^{\star} P$-value

$50 \quad 63.85$ to 0.51

$50 \quad 63.83$ to 0.51

0.97

61.22 to 0.89

64.07 to 1.21

0.01

58.91 to 0.85

62.08 to 1.17

0.01

62.8 to 0.58

62.9 to 0.49 
proximal region and are located deeply at the elbow. Therefore, they are more possibly prone to damages. ${ }^{[10]}$ Some researches have also indicated that the sensitivity of this method in evaluation of ulnar neuropathy would be increased when recording is done from FDI in comparison with ADM. ${ }^{[1,2,7,10]}$ However, the results are controversial. Some authors indicated no difference between two conditions, ${ }^{[6,11]}$ whereas other authors have shown that recording from ADM is more sensitive than FDI. ${ }^{[12]}$

All of the studies mentioned above have been performed on the basis of equality of the normal ulnar NCV values at the elbow, recorded from either ADM or FDI in healthy individuals. ${ }^{[1,2,7,10,11]}$ Conversely, the results of this study have shown that the minimal ulnar NCV at the elbow, recorded from FDI $(45.65 \mathrm{~m} / \mathrm{s})$, is less than the one recorded from ADM $(47.39 \mathrm{~m} / \mathrm{s})$. Besides, it has been evidenced that the minimal normal range of the difference between motor ulnar NCV at the elbow and forearm, recorded from FDI $(18.11 \mathrm{~m} / \mathrm{s})$ is more than the one recorded from ADM $(16.4 \mathrm{~m} / \mathrm{s})$.

As a result both records from ADM or FDI have their own normal range of values. For this reason, using the normal values of ADM as the basis to evaluate measurements, recorded from FDI, could lead to a false positive diagnosis of subjects, suspicious of ulnar neuropathy at the elbow that would be otherwise considered as normal. The possible cause of this difference in normal value between NCS of the ADM and FDI may be due to differences in the types of nerve fibers in terms of speed of conduction. Additionally, it may be following to the mild and repeated damages to the nerve fascicles of FDI by time with daily activities, as they are more superficial. Therefore, more investigation should be performed.

Other studies are necessary both in healthy people and in patients to confirm the idea whether FDI recording should replace or simply complement ADM recording. However, in the current study, the reduction of NCV across the elbow was more prominent when recorded from FDI than recorded from ADM.

\section{References}

1. Dumitru D, Zwarts MJ. Focal Peripheral Neuropathies. In: Dumitru D, Amato AA, Zwarts MJ, editors. Electrodiagnostic medicine. $2^{\text {nd }}$ ed. Hanley and Belfus Inc: Philadelphia; 2002. p. 1076-81.

2. Kothari MJ, Heistand M, Rutkore SB. Three ulnar nerve conduction studies in patients with ulnar neuropathy at the elbow. Arch Phys Med Rehabil 1998;79:87-9

3. Kincaid JC, Phillips LH $2^{\text {nd }}$, Daube JR. The evaluation of suspected ulnar neuropathy at the elbow. Arch Neurol 1986;43:44-7.

4. Neary O, Ochoa J, Gilliatt RW. Sub-clinical entrapment neuropathy. J Neurol Sci 1975;24:283-98.

5. Kincaid JC. AAEE minimonograph \#31: The electrodiagnosis of ulnar neuropathy at the elbow. Muscle Nerve 1988;11:1005-15.

6. Chan KM, Andres LP, Polykovskaya Y, Brown WF. The effects of training through high-frequency electrical stimulation on the physiological properties of single human thenar motor units. Muscle Nerve 1999;22:186-95.

7. Bhalas RP. Electrodiagnosis of ulnar nerve lesions at the elbow. Arch Phys Med Rehabil 1976;57:206-12

Kimura I, Ayyar DR. Early diagnosis of ulnar nerver entrapment neuropathy at the elbow. Tohokuj Exp Med 1984;182:165-72.

9. Beekman R, Van Der Plas JP, Uitdehaag BM, Schellens RL, Visser LH. Clinical, electrodiagnostic, and sonographic studies in ulnar neuropathy at the elbow. Muscle Nerve 2004;30:202-8.

10. Stewart JD. The variable clinical manifestations of ulnar neuropathies at the elbow. J Neurol Neurosurg Psychiatry $1987 ; 50: 252-8$.

11. Tackmann W, Vogel P, Kaeser HE, Ettlin T. Sensitivity and localizing significance of motor and sensory electroneurographic parameters in the diagnosis of ulnar nerve lesions at the elbow. A reappraisal. J Neurol 1984;231:204-11.

12. Shakir A, Micklesen PJ, Robinson LR. Which motor nerve conduction study is best in ulnar neuropathy at the elbow? Muscle Nerve 2004;29:585-90

Accepted on 22-12-2006

Source of Support: Nil, Conflict of Interest: None declared.

\section{Author Help: Reference checking facility}

The manuscript system (www.journalonweb.com) allows the authors to check and verify the accuracy and style of references. The tool checks the references with PubMed as per a predefined style. Authors are encouraged to use this facility before submitting articles to the journal.

- The style as well as bibliographic elements should be $100 \%$ accurate to get the references verified from the system. A single spelling error or addition of issue number / month of publication will lead to error to verifying the reference.

- $\quad$ Example of a correct style

Sheahan P, O'leary G, Lee G, Fitzgibbon J. Cystic cervical metastases: Incidence and diagnosis using fine needle aspiration biopsy. Otolaryngol Head Neck Surg 2002;127:294-8.

- $\quad$ Only the references from journals indexed in PubMed would be checked.

- $\quad$ Enter each reference in new line, without a serial number.

- Add up to a maximum 15 reference at time.

- If the reference is correct for its bibliographic elements and punctuations, it will be shown as CORRECT and a link to the correct article in PubMed will be given.

- If any of the bibliographic elements are missing, incorrect or extra (such as issue number), it will be shown as INCORRECT and link to possible articles in PubMed will be given. 